\title{
Carcinosarcoma (Malignant Mixed Muellerian Tumor) of the Ovary-A Single Institution Experience of 25 years
}

\author{
Edgar Petru*, Josef Haas, Sanja Beganovic, Vassiliki Kolovetsiou and Nora Woltsche \\ Department of Obstetrics and Gynecology, Medical University, Auenbruggerplatz 14, 8036 Graz, Austria
}

\begin{abstract}
Carcinosarcoma (malignant mixed muellerian tumor) of the ovary is a rare and aggressive tumor entity. The present study retrospectively evaluated potential prognostic factors in a series of 26 consecutive patients with primary carcinosarcoma of the ovary diagnosed and treated at the Department of Obstetrics and Gynecology of the Medical University of Graz over a 25-year period. Neither the univariate nor the multivariate analysis identified a subgroup of patients with favorable progression-free survival.

With regard to overall survival, univariate analysis revealed a favorable trend for patients $<70$ years versus those $>70$ years of age ( 5 -year survival of $22 \%$ versus 0 , respectively; $p=0.067$ ). In addition, in patients with a preoperative lactate dehydrogenase $(\mathrm{LDH})$-value of $<200 \mathrm{U} / \mathrm{L}$, also a trend towards better overall survival was observed as compared to those with a LDH concentration of $>200 \mathrm{U} / \mathrm{L}(\mathrm{p}=0.052)$. In multivariate analysis, age of the patients $<70$ years was associated with an improved overall survival as compared to those $>70$ years ( $34 \%$ versus 0 at 5 years, respectively; $p=0.008$ ).

None of the other factors investigated including preoperative hemoglobin, platelet counts and lactate dehydrogenase, preoperative Karnofsky status, type of surgery, ascites, type of bowel involvement, FIGO stage, residual tumor, pelvic lymph node status, existence of a homologous or heterologous carcinosarcoma type, grade of differentiation, or postoperative chemotherapy revealed prognostic information.

The majority of recurrences were located in the pelvis, liver parenchyma and peritoneum.

Although carcinosarcomas are regarded to be of epithelial origin nowadays and thus are included in trials with epithelial ovarian cancer, the authors believe that this group should be analyzed separately due to its inferior prognosis and the urgent need for intensified research in this specific tumor subtype.
\end{abstract}

\section{Introduction}

Carcinosarcoma (malignant mixed muellerian tumor) of the ovary represents a rare and aggressive tumor entity. Carcinosarcomas of the ovary are about three times less prevalent than those of the uterus [1]. According to the WHO, carcinosarcomas are regarded as metaplastic carcinomas and are supposed to be of epithelial monoclonal origin.

The mesenchymal component of the carcinosarcoma either consists of homologous or heterologous elements. Homologous carcinosarcomas contain sarcomatous elements originating from tissue normally being present in the ovary. The heterologous components usually contain malignant osteoid, chondroid or rhabdomyoid cells. Overall, homologous sarcomatous tumors do not carry a better prognosis than the heterogenous counterparts [2-5].

The epithelial component more often represents multiple than singular components. Serous components are more common than endometrioid ones and have been demonstrated to be associated with an inferior prognosis in some studies [2]. Clear cell and squamous cancer components are rare. In the majority of cases, the development of metastases/tumor progression is caused by the epithelial component [6].

Staging of ovarian carcinosarcomas is carried out using that from ovarian cancers [7]. The prognosis of carcinosarcomas of the ovary is more favorable than that of the uterus [1]. However, they carry a significantly worse prognosis than (high-grade) serous carcinomas of the ovary [8-10].

Standard treatment of ovarian carcinosarcoma consists of bilateralsalpingo-oophorectomy, total abdominal hysterectomy, debulking of peritoneal metastases, and lymphadenectomy $[1,2,9]$.
The present study retrospectively evaluated potential prognostic factors in a series of 26 consecutive patients with carcinosarcoma of the ovary diagnosed and treated at the Dept. of Obstetrics and Gynecology of the Medical University of Graz over a 25-year period.

\section{Materials and Methods}

26 consecutive patients with primary carcinosarcoma of the ovary were diagnosed and treated at the Department of Obstetrics and Gynecology of the Medical University of Graz, Austria, between 1987 and 2011. The following factors were retrospectively analyzed on the basis of an institutional computer data bank: Patient's age, preoperative hemoglobin, platelet counts and lactate dehydrogenase, preoperative Karnofsky status, type of surgery, ascites, type of bowel involvement, FIGO stage, residual tumor, pelvic lymph node status, existence of a homologous or heterologous carcinosarcoma type, grade of differentiation, postoperative chemotherapy, localization of recurrence/metastasis, last date of follow-up and tumor status at last date of follow-up.

\section{Results}

Neither the univariate nor the multivariate analysis identified a subgroup of patients with favorable progression-free survival.

"Corresponding Author: Dr. Edgar Petru, Department of Obstetrics and Gynecology, Medical University, Auenbruggerplatz 14, 8036 Graz, Austria; E-mail: edgar.petru@medunigraz.at

Citation: Petru E, Haas J, Beganovic S, Kolovetsiou V, Woltsche N (2015) Carcinosarcoma (Malignant Mixed Muellerian Tumor) of the Ovary-A Single Institution Experience of 25 years. Int J Gynecol Clin Pract 2: 107. doi: http:// dx.doi.org/10.15344/2394-4986/2015/107

Copyright: @ 2015 Petru et al. This is an open-access article distributed under the terms of the Creative Commons Attribution License, which permits unrestricted use, distribution, and reproduction in any medium, provided the original author and source are credited. 
Citation: Petru E, Haas J, Beganovic S, Kolovetsiou V, Woltsche N (2015) Carcinosarcoma (Malignant Mixed Muellerian Tumor) of the Ovary-A Single Institution Experience of 25 years. Int J Gynecol Clin Pract 2: 107. doi: http://dx.doi.org/10.15344/2394-4986/2015/107

Page 2 of 3

With regard to overall survival, univariate analysis revealed a favorable trend for patients $<70$ years versus those $>70$ years of age (5-year survival of $22 \%$ versus 0 , respectively; $p=0.067$ ). In addition, in patients with a preoperative lactate dehydrogenase (LDH)-value of $<200 \mathrm{U} / \mathrm{L}$, a trend towards better overall survival was observed as compared to those with a LDH concentration of $>200 \mathrm{U} / \mathrm{L}(\mathrm{p}=0.052)$.

On multivariate analysis, age of the patients $<70$ years was associated with an improved overall survival as compared to those $>70$ years ( $34 \%$ versus 0 at 5 years, respectively; $p=0.008$; Figure 1 ).

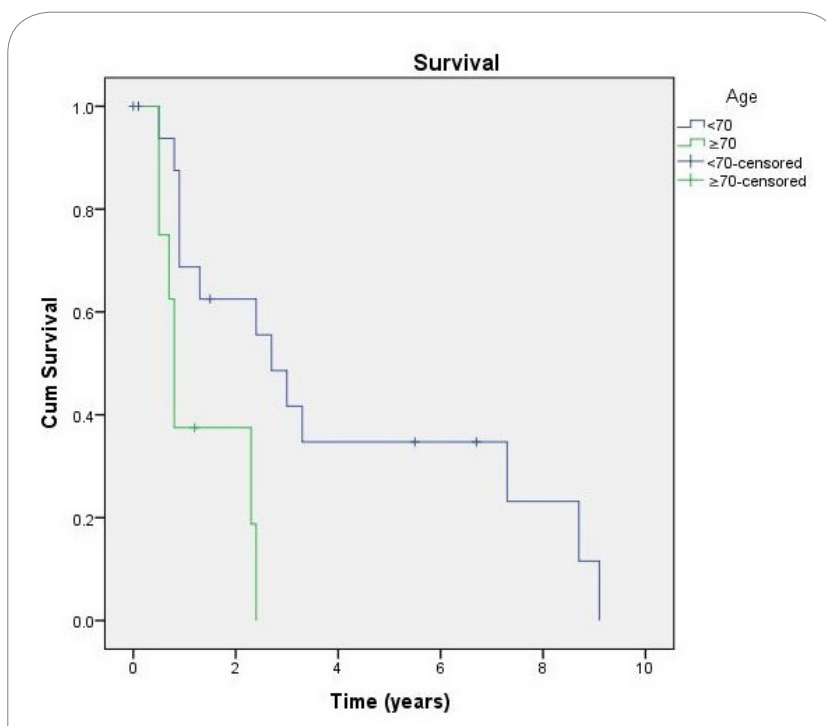

Figure 1: Overall survival of the 26 study patients with stage I-III carcinosarcoma of the ovary aged $<70$ years versus those $>70$ years $(p=$ $0.008)$

None of the other factors investigated including preoperative hemoglobin, platelet counts and lactate dehydrogenase, preoperative Karnofsky status, type of surgery, ascites, type of bowel involvement, FIGO stage, residual tumor, pelvic lymph node status, existence of a homologous or heterologous carcinosarcoma type, grade of differentiation, or postoperative chemotherapy revealed prognostic information.

All carcinosarcomas recurred or progressed. The sites of first recurrence are depicted in Table 1 the majority of them being located in the pelvis, parenchymal liver and peritoneum.

\section{Discussion}

Patients' age was the only factor being demonstrated to independently influence overall survival in the 26 patients with primary ovarian carcinosarcoma of stages I to III treated in the present study. Patients aged $>70$ years carried a significantly worse prognosis than younger patients $(\mathrm{p}=0.008$, Figure 1$)$. This finding is supported by several other studies in which older patients also were found to exert a significantly worse survival rate $[1,2,5,11]$.

Overall, prognosis of primary ovarian carcinosarcoma is particularly poor. Median survival was reported to range between seven and 26months, respectively. In the majority of studies, the median survival was around 11 months $[1-5,9,14,15]$.

Similarly to the present study, also previous reports usually contained small numbers of patients only [2,3,5,12,16-19].

\begin{tabular}{|c|c|}
\hline & No. of patients (\%) \\
\hline Median age, years & 64 (range 42-91) \\
\hline \multicolumn{2}{|l|}{ Age } \\
\hline$<60$ years & $11(42 \%)$ \\
\hline$>60$ years & $15(58 \%)$ \\
\hline \multicolumn{2}{|l|}{ Preoperative Karnofsky performance status } \\
\hline$>80$ & $17(65 \%)$ \\
\hline$<80$ & $15(58 \%)$ \\
\hline \multicolumn{2}{|l|}{ Preoperative haemoglobin $(\mathrm{Hb})$ level } \\
\hline$>10 \mathrm{mg} / \mathrm{dl}$ & $15(58 \%)$ \\
\hline$<10 \mathrm{mg} / \mathrm{dl}$ & $11(42 \%)$ \\
\hline \multicolumn{2}{|l|}{ Preoperative platelet counts } \\
\hline$<200 \mathrm{G} / \mathrm{L}$ & $3(12 \%)$ \\
\hline$>200 \mathrm{G} / \mathrm{L}$ & $23(88 \%)$ \\
\hline \multicolumn{2}{|l|}{ Preoperative lactate dehydrogenase (LDH) level } \\
\hline$<200 \mathrm{U} / \mathrm{L}$ & $4(15 \%)$ \\
\hline$>200 \mathrm{U} / \mathrm{L}$ & $20(77 \%)$ \\
\hline Not determined & $2(8 \%)$ \\
\hline \multicolumn{2}{|l|}{ Preoperative ultrasound } \\
\hline Solid-cystic tumour & $18(69 \%)$ \\
\hline Cystic tumour with papillary projections & $7(27 \%)$ \\
\hline No suspicious findings of the adnexae & $1(4 \%)$ \\
\hline \multicolumn{2}{|l|}{ FIGO stage } \\
\hline $\mathrm{Ib}$ & $1(4 \%)$ \\
\hline Ic & $2(8 \%)$ \\
\hline $\mathrm{IIb}$ & $1(4 \%)$ \\
\hline IIIa & $3(12 \%)$ \\
\hline IIIb & $1(4 \%)$ \\
\hline IIIc & $18(69 \%)$ \\
\hline \multicolumn{2}{|l|}{ Intraoperative ascites } \\
\hline None & $8(31 \%)$ \\
\hline$<500 \mathrm{ml}$ & $9(35 \%)$ \\
\hline$>500 \mathrm{ml}$ & $9(35 \%)$ \\
\hline \multicolumn{2}{|l|}{ Bowel involvement } \\
\hline Small bowel & $6(23 \%)$ \\
\hline Large bowel & $9(35 \%)$ \\
\hline Sigmoid colon/rectum & $13(50 \%)$ \\
\hline \multicolumn{2}{|l|}{ Primary surgery } \\
\hline $\begin{array}{l}\text { Bilateral salpingo-oophorectomy }(\mathrm{BSO})+\text { total abdominal } \\
\text { hysterectomy }(\mathrm{TAH})+\text { omentectomy }(\mathrm{OM})\end{array}$ & $14(54 \%)$ \\
\hline $\mathrm{BSO}+\mathrm{TAH}+\mathrm{OM}+$ pelvic lymphadenectomy & $12(46 \%)$ \\
\hline \multicolumn{2}{|l|}{ Residual disease } \\
\hline None & $18(69 \%)$ \\
\hline$<1 \mathrm{~cm}$ & $1(4 \%)$ \\
\hline$<2 \mathrm{~cm}$ & $2(8 \%)$ \\
\hline$>2 \mathrm{~cm}$ & $5(19 \%)$ \\
\hline \multicolumn{2}{|l|}{ Sarcoma component } \\
\hline Homologous & $7(27 \%)$ \\
\hline Heterologous & $19(73 \%)$ \\
\hline \multicolumn{2}{|l|}{ Grading } \\
\hline G1 & $1(4 \%)$ \\
\hline G2 & $2(8 \%)$ \\
\hline G3 & $23(77 \%)$ \\
\hline \multicolumn{2}{|l|}{ Chemotherapy } \\
\hline Platinum-based & $18(69 \%)$ \\
\hline Non-platinum-based & $1(4 \%)$ \\
\hline None $^{*}$ & $7(27 \%)$ \\
\hline
\end{tabular}

Table 1: Pretreatment characteristics of the 26 study patients with stage I to III primary carcinosarcoma of the ovary.

* Two patients received radiotherapy. 
Citation: Petru E, Haas J, Beganovic S, Kolovetsiou V, Woltsche N (2015) Carcinosarcoma (Malignant Mixed Muellerian Tumor) of the Ovary-A Single Institution Experience of 25 years. Int J Gynecol Clin Pract 2: 107. doi: http://dx.doi.org/10.15344/2394-4986/2015/107

Higher disease stage was reported to negatively influence survival in the majority of studies reported $[1,4,12,13,16,20-23]$.

Higher residual tumor burden has also been reported to be associated with an inferior prognosis [2, 9,13-15,22,24]. In the present study, $69 \%$ of patients had optimal debulking surgery. Nevertheless, none of them survived five years without evidence of disease. This fact underlines the need of effective systemic therapy in carcinosarcomas of the ovary.

The use of platinum-based chemotherapy was found predictive of survival in some studies $[11,13,15,21]$. The combinations of cisplatinum and ifosfamide as well as carboplatin/paclitaxel have been studied more in detail $[5,11,13-15,18,23]$. However, there exists no adjuvant standard treatment for this disease.

This is the first (small) study which describes the patterns of initial recurrence/progression. There was a propensity towards pelvic, parenchymal liver, and peritoneal metastases in our cohort (Table 2). In contrast to classical epithelial ovarian cancer, the rate of parenchymal liver metastases as first site of recurrence seems was elevated (35\%, Table 2$)$

\begin{tabular}{|l|l|}
\hline & No. of patients (\%) \\
\hline Pelvis & $8(31 \%)$ \\
\hline Liver & $6(23 \%)$ \\
\hline Peritoneum & $5(19 \%)$ \\
\hline Liver and pelvis & $2(8 \%)$ \\
\hline Liver and peritoneum & $1(4 \%)$ \\
\hline Paraaortic & $1(4 \%)$ \\
\hline Peritoneum and pelvis & $1(4 \%)$ \\
\hline Adrenal gland & $1(4 \%)$ \\
\hline
\end{tabular}

Table 2: Localization of first clinical recurrence/tumor progression in the 26 study patients with stage I to III primary carcinosarcoma of the ovary.

\section{Conclusion}

In conclusion, the present study on carcinosarcoma of the ovary demonstrated age $>70$ years at diagnosis to be associated with a particularly unfavorable prognosis. Although carcinosarcomas are regarded to be of epithelial origin nowadays and thus are included in trials with epithelial ovarian cancer, the authors believe that this group should be analyzed separately due to its inferior prognosis and the urgent need for intensified research in this specific tumor entity.

\section{Competing Interests}

The authors declare that they have no competing interests.

\section{Author Contributions}

Edgar Petru: Substantially contributed to the study conception and design.

Edgar Petru and Sanja Beganovic: contributed to the acquisition, analysis, and interpretation of data.

Vassiliki Kolovetsiou and Nora Woltsche: Drafting manuscript and approved the final version of the manuscript towards publication.

\section{References}

1. Garg G, Shah JP, Kumar S, Bryant CS, Munkarah A, et al. (2010) Ovarian and uterine carcinosarcomas: a comparative analysis of prognostic variables and survival outcomes. Int J Gynecol Cancer 20: 888-894.
2. Athavale R, Thomakos N, Godfrey K, Kew F, Cross P, et al. (2007) The effect of epithelial and stromal tumor components on FIGO stages III and IV ovarian carcinosarcomas treated with primary surgery and chemotherapy. Int J Gynecol Cancer 17: 1025-1030.

3. Barakat RR, Rubin SC, Wong G, Saigo PE, Markman M, et al. (1992) Mixed mesodermal tumor of the ovary: analysis of prognostic factors in 31 cases. Obstet Gynecol 80: 660-664.

4. Hellström AC, Tegerstedt G, Silfverswärd C, Pettersson F (1999) Malignant mixed müllerian tumors of the ovary: histopathologic and clinical review of 36 cases. Int J Gynecol Cancer 9: 312-316.

5. Inthasorn P, Beale P, Dalrymple C, Carter J (2003) Malignant mixed mullerian tumour of the ovary: prognostic factor and response of adjuvant platinum-based chemotherapy. Aust N Z J Obstet Gynaecol 43: 61-64.

6. Sreenan J, Hart W (1995) Carcinosarcomas of the female genital tract A pathologic study of 29 metastastic tumors: Further evidence of the dominant role of the epithelial component and the conversion theory of histogenesis. Am J Surg Pathol 19: 666-674.

7. Petru E, Lück HJ, Stuart G, Gaffney D, Millan D, et al. (2009) Gynecologic Cancer Intergroup ( $\mathrm{GCIG}$ ) proposals for changes of the current FIGO staging system. Eur J Obstet Gynecol Reprod Biol 143: 69-74.

8. Barnholtz-Sloan JS, Morris R, Malone JM Jr, Munkarah AR (2004) Survival of women diagnosed with malignant, mixed mullerian tumors of the ovary (OMMMT). Gynecol Oncol 93: 506-512.

9. Brown E, Stewart M, Rye T, Al-Nafussi A, Williams AR, et al. (2004) Carcinosarcoma of the ovary: 19 years of prospective data from a single center. Cancer 100: 2148-2153.

10. Rauh-Hain JA, Diver EJ, Clemmer JT, Bradford LS, Clark RM, et al. (2013) Carcinosarcoma of the ovary compared to papillary serous ovarian carcinoma: a SEER analysis. Gynecol Oncol 131: 46-51.

11. Rauh-Hain JA, Shoni M, Schorge JO, Goodman A, Horowitz NS, et al. (2013) Prognostic determinants in patients with uterine and ovarian carcinosarcoma. J Reprod Med 58: 297-304.

12. Asghar U, Imseeh G, Kirkwood A, Widschwendter M, Olaitan A, et al. (2014) 930P- A retrospective single institution study evaluating clinical outcome and prognostic markers for endometrial and ovarian carcinosarcomas. Ann Oncol.

13. Cicin I, Saip P, Eralp Y, Selam M, Topuz S, et al. (2008) Ovarian carcinosarcomas: Clinicopathological prognostic factors and evaluation of chemotherapy regimens containing platinum. Gynecol Oncol 108: 136-140.

14. Harris MA, Delap LM, Sengupta PS, Wilkinson PM, Welch RS, et al. (2003) Carcinosarcoma of the ovary. Br J Cancer 88: 654-657.

15. Rutledge TL, Gold MA, McMeekin DS, Huh WK, Powell MA, et al. (2006) Carcinosarcoma of the ovary-a case series. Gynecol Oncol 100: 128-132.

16. Ariyoshi K, Kawauchi S, Kaku T, Nakano H, Tsuneyoshi M (2000) Prognostic factors in ovarian carcinosarcoma: a clinicopathological and immunohistochemical analysis of 23 cases. Histopathology 37: 427-436.

17. Migalli C, Lima J, Della Pepa C, Kaye S, Gore M, et al. (2014) Ovarian carcinosarcoma management: A retrospective analysis of the royal Marsden experience. Ann Oncol 25: 902.

18. Silasi DA, Illuzzi JL, Kelly MG, Rutherford TJ, Mor G, et al. (2008) Carcinosarcoma of the ovary. Int J Gynecol Cancer 18: 22-29.

19. Zorzou MP, Markaki S, Rodolakis A, Kastritis E, Bozas G, et al. (2005) Clinicopathological features of ovarian carcinosarcomas: a single institution experience. Gynecol Oncol 96: 136-142.

20. Chang J, Sharpe JC, A'Hern RP, Fisher C, Blake P, et al. (1995) Carcinosarcoma of the ovary: incidence, prognosis, treatment and survival of patients. Ann Oncol 6: 755-758.

21. Lu CH, Chen IH, Chen YJ, Wang KL, Qiu JT, et al. (2014) Primary treatment and prognostic factors of carcinosarcoma of the ovary, fallopian tube and peritoneum: a Taiwanese Gynecologic Oncology Group Study. Int J Gynecol Cancer 24: 506-512.

22. Morrow CP, D'Ablaing G, Brady L, Blessing J, Hreshchyshyn MM (1984) A clinical and pathologic study of 30 cases of malignant mixed mullerian epithelial and mesenchymal ovarian tumors: A gynecologic oncology group study. Gynecol Oncol 18: 278-292.

23. Duska LR, Garrett A, Eltabbakh GH, Oliva E, Penson R, et al. (2002) Paclitaxel and platinum chemotherapy for malignant mixed müllerian tumors of the ovary. Gynecol Oncol 85: 459-463. 